\title{
Leriche Syndrome: Percutaneous Treatment with Mechanical Thrombectomy: A Case Report
}

\author{
Laganà $\mathrm{D}^{* 1}$, Ciranni $\mathrm{S}^{2}$, Minici $\mathrm{R}^{1}$ and Mazzarella $\mathrm{G}^{1}$ \\ ${ }^{1}$ Division of Radiology, Department of Clinical and Experimental Medicine, "Magna Græcia” University, Catanzaro, \\ Italy \\ ${ }^{2}$ Division of Vascular Surgery, Department of Clinical and Experimental Medicine, "Magna Græcia" University, Cat- \\ anzaro, Italy
}

*Corresponding author: Laganà D, Division of Radiology, Department of Clinical and Experimental Medicine, University "Magna Graecia" of Catanzaro, Viale Europa, Catanzaro 88100, Italy, Fax: +39 09613647395, Tel: +3909613647213, E-mail: domenico.lagana@unicz.it

Citation: Laganà D, Ciranni S, Minici R, Mazzarella G (2017) Leriche Syndrome: Percutaneous Treatment with Mechanical Thrombectomy: A Case Report. J Cas Rep Stud 6(1): 10. doi: 10.15744/2348-9820.6.101

Received Date: October 18, 2017 Accepted Date: February 26, 2018 Published Date: February 28, 2018

\begin{abstract}
Leriche Syndrome is the thrombotic obliteration of the aortic bifurcation. According to Aorto-iliac Occlusive Disease (AIOD) classification by the Trans Atlantic Inter-Society Consensus (TASC II), Leriche Syndrome belongs to type D lesions, for which surgery is the treatment of choice. Long-term primary patency rates for open surgery are undoubtedly superior to endovascular intervention with stent placement; however, secondary patency rates are comparable. Furthermore, open reconstructionsare related to higher operative morbidity, mortality, length of hospital stay and short-term costs.Hence, the decision as to whether to choose endovascular or open intervention requires a balance between the extent of patient's disease, the ability for patient to withstand a significant open operation without serious complication, and the surgeon's comfort and expertise in both open and endovascular aortoiliac procedures. There is a lack of datain literature, regarding mechanical thrombectomy in percutaneous treatment of aortoiliac occlusion. Our experience sought to demonstrate that rotational mechanical thrombectomy, performed with Rotarex device, could be a feasible and safe solution as an adjunct to stenting.
\end{abstract}

Keywords: Leriche Syndrome; Aortoiliac occlusion; Rotational mechanical thrombectomy; Percutaneous treatment; Kissing balloons

\section{Introduction}

Leriche Syndrome was firstly described in 1948 by Renè Leriche, as the syndrome of thrombotic obliteration of the aortic bifurcation [1]. It includes the triad of erectile dysfunction, claudication and decreased/absent pulses due to aortoiliac occlusion. Erectile dysfunction comes as the inability to keep a stable erection, caused by blood flow insufficiency to fill spongious bodies. Claudication is not the well-known "intermittent claudication", but an extreme liability to fatigue of both lower limbs, with related atrophy. Decreased or absent pulses can be found, on either side, in the dorsal pedis, tibial, femoral and iliac arteries: legs and feet look like pale marble. However, there are no trophic changes on skin and nails, although impaired wound healing is not uncommon [1]. The Ankle Brachial Index is a non-invasive, cheap and reliable method to screen patient with an evocative clinical history, addressing positive cases to radiological imaging [2]. Usually, a computed tomography angiography with runoff is performed, demonstrating a complete infrarenal aorto-iliac occlusion, with significant collateral circulation, sustained by muscular, diaphragmatic, epigastric, ilio-lumbar, etc., anastomoses, which allow reconstitution of distal femoral arteries [3]. Treatment is aimed atrelievesymptoms related to aortic occlusion as well as the prevention of proximal propagation of thrombus. According to Aorto-iliac Occlusive Disease (AIOD) classification by the Trans Atlantic Inter-Society Consensus (TASC II), Leriche Syndrome belongs to type D lesions, for which surgery is the recommended treatment of choice [4]. This is a grade C recommendation, so it is based on evidence obtained from expert committee reports or opinions and/or clinical experiences of respected authorities, with no applicable studies of good quality. In this lack of strong evidence, a recent meta-analysis of endovascular treatment for extensive AIOD (TASC C and D lesions), witha total of 19 non-randomized cohort studies and 1711 patients included, shows that, although 4- and 5-year primary patency rates for endovascular repair were lower compared to open surgical treatment, the secondary patency rates were comparable [5]. Another two studies retrospectively compared open and endovascular therapy. Significantly lower perioperative morbidity and shorter hospital stay was reported in the endovascular group. Three- and four-year primary 
patency rates were also significantly lower for the endovascular group (69\% vs $93 \%, \mathrm{P}=0.013$ and $74 \%$ vs $93 \%, \mathrm{P}=0.002)$, however secondary patency was comparable with surgical repair ( $89 \%$ vs $100 \%, \mathrm{P}>0.05$ and $95 \%$ vs $97 \%, \mathrm{P}=0.3)[6,7]$. A meta-analysis has proved that the technical success rate was higher after stent placement than PTA, and the risk of long-term failure was reduced [8]. So, endovascular treatment of Leriche Syndrome with stent placement seems to be a feasible and safe solution as it is associated with excellent mid-term clinical outcomes, despite TASC-II guidelines.

\section{Case}

A 53-year-old man was admitted, after several months of worsening claudication, for computed-tomography angiography with runoff. Imaging demonstrated occlusion of infrarenal aorta, extended to aortoiliac bifurcation and common iliac arteries (Figure 1). Hence, he was evaluated by vascular surgeons, but he wasn't considered a candidate for surgery, cause his severe post-ischemic congestive heart failure, so he was candidates for percutaneous treatment.A patient came to our attention and he was subjected to the interventional procedure described below.

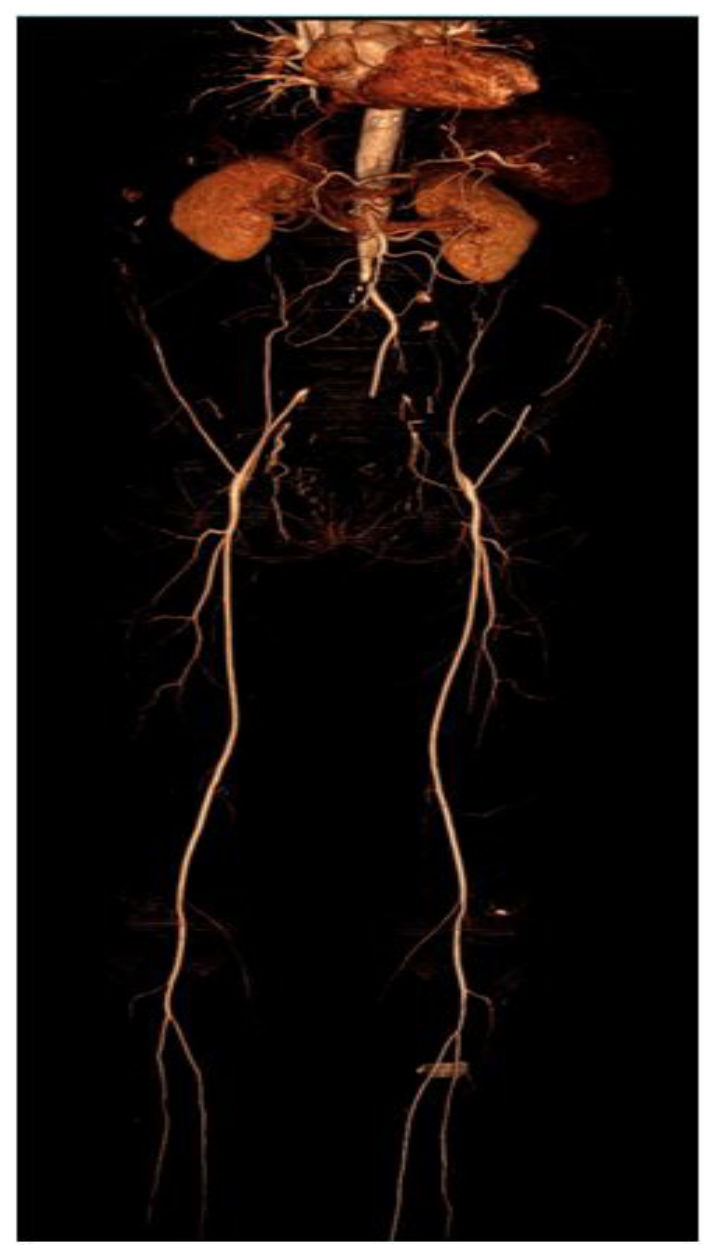

Figure 1: CT angiography reconstruction

After a transradial puncture, a 5F valved introducer sheath (Terumo, Tokyo, Japan) was inserted, and diagnostic angiography was performed with a Pig - Tail catheter (Cordis, NJ, USA). This documented aortic occlusion immediately downstream of the inferior mesenteric artery with collateral circulationensuring recanalizationof the internal and external iliac artery bilaterally (Figure 2). Subsequently, after a right transfemoral puncture, an $8 \mathrm{~F}$ valved introducer sheath (Cordis, Warren, NJ, USA) was inserted and the occlusion was crossed usinga hydrophilic guidewire (GlidewireTerumo, Tokyo, Japan) (Figure 3); then, the guidewire was replaced with 0.014-in. Hydrophilic guidewire and the rotational thrombectomy device (Straub Medical Rotarex ) was put (Figure 4). Then the right iliac axis and aortic stretch downstream of the inferior mesenteric artery was disengaged and nitinol stent $14 \mathrm{~mm}$ in diameter and $4 \mathrm{~cm}$ in length (Cordis, Johnson \& Johnson, Miami Lakes, FL, USA) was positioned (Figure 5). After checking the uniform opacity of the vessel with diagnostic angiography, a $6 \mathrm{~F}$ valved introducer sheath (Terumo, Tokyo, Japan) was inserted, after a left transfemoral puncture. Through femoral vascular accesses, the catheter with a $6 \mathrm{~mm}$ thick and $10 \mathrm{~cm}$ long balloon ( Cordis, Miami, FL, USA) were introduced; at the level of iliac bifurcation, angioplasty, with technique of "Kissing Balloons", was then performed (Figure 6). Regular and uniform opacity of infrarenal aorta and common iliac artery has been documented with control angiography (Figure 7). Finally, with an 8F Angioseal device (St. Jude Medical Inc.) on the right and a 6F Angioseal device on the left, vascular femoral accesses were closed, while, with inflatable bracelet, radial access. 


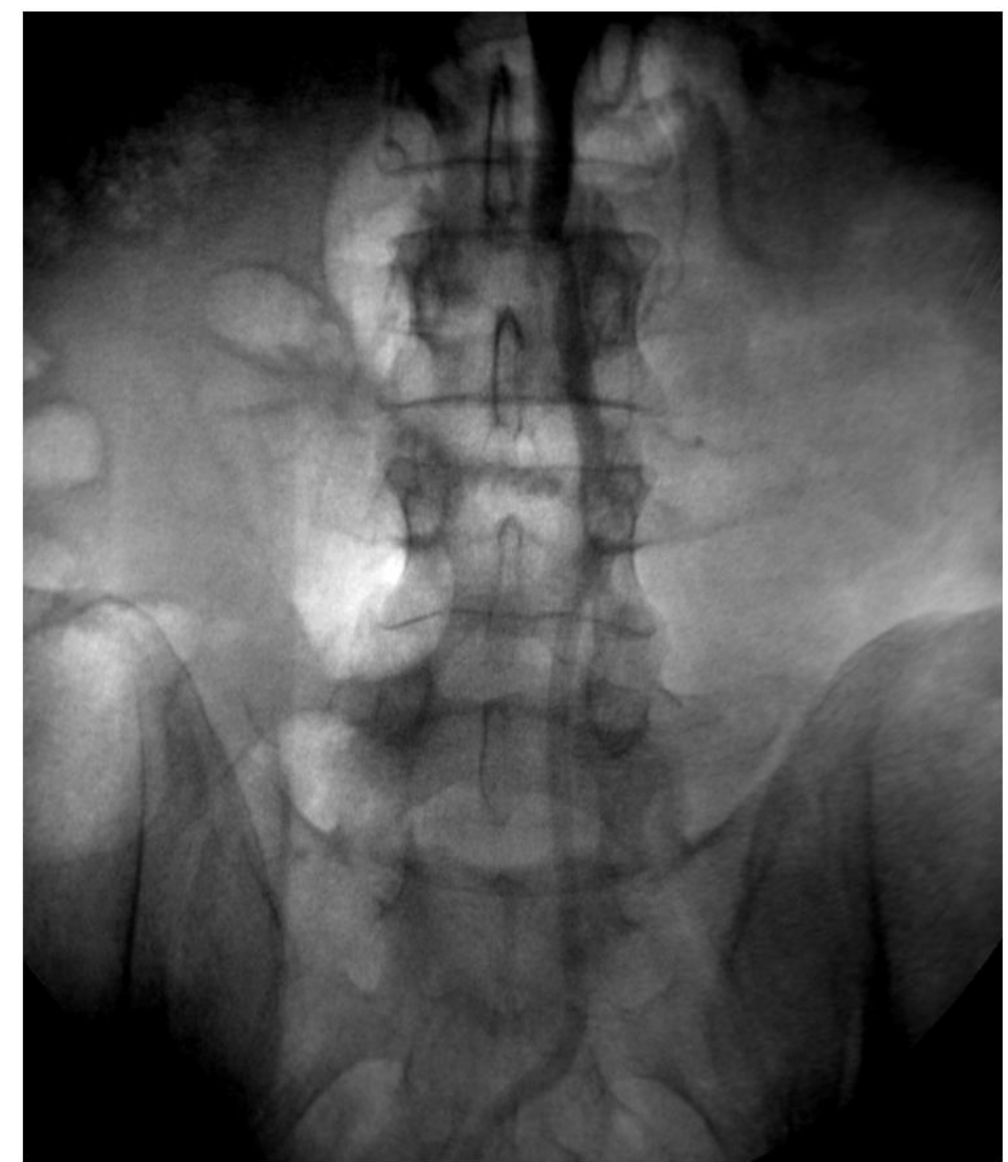

Figure 2: Aortic occlusion immediately downstream of the inferior mesenteric artery with collateral circulation ensuring recanalization of the internal and external iliac artery bilaterally

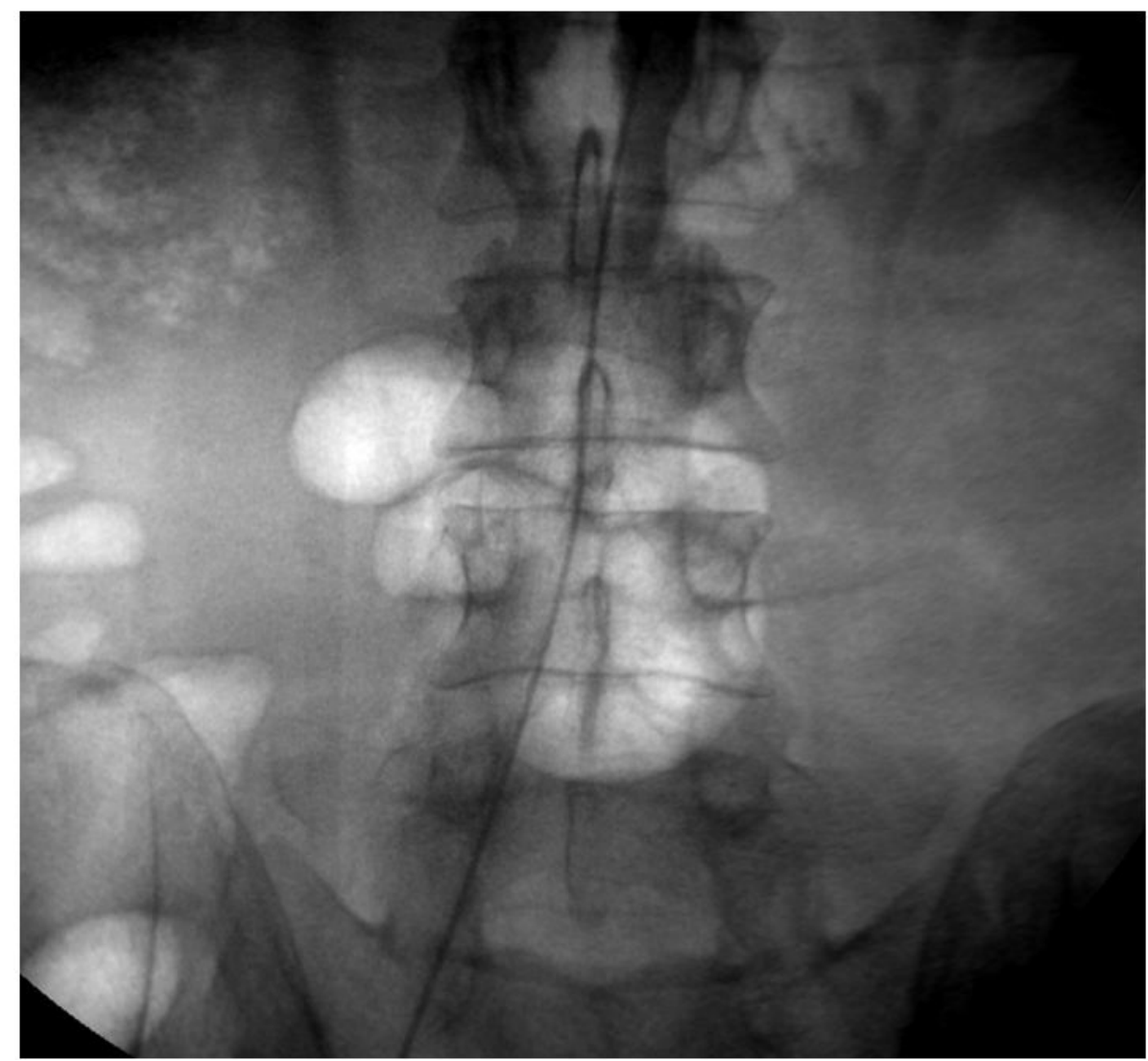

Figure 3: Occlusion crossed using hydrophilic guide wire 


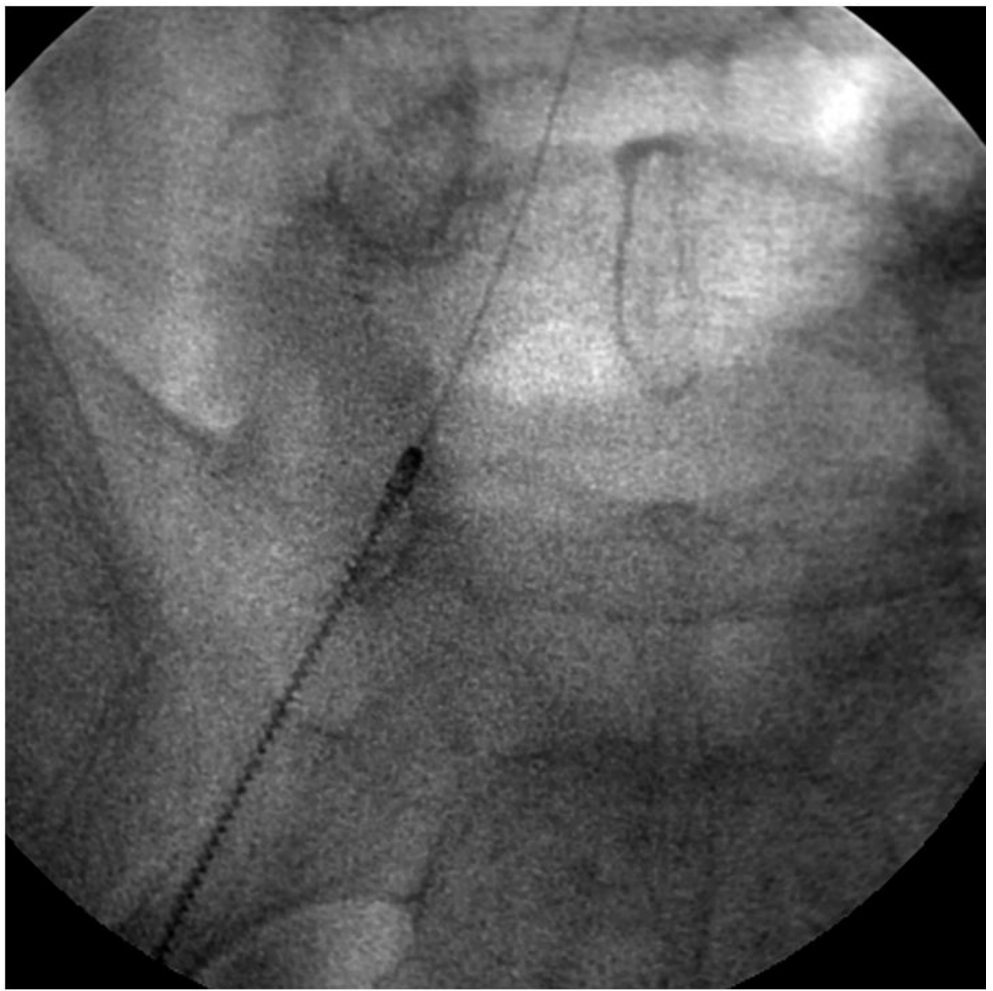

Figure 4: Rotational thrombectomy device (Straub Medical Rotarex)

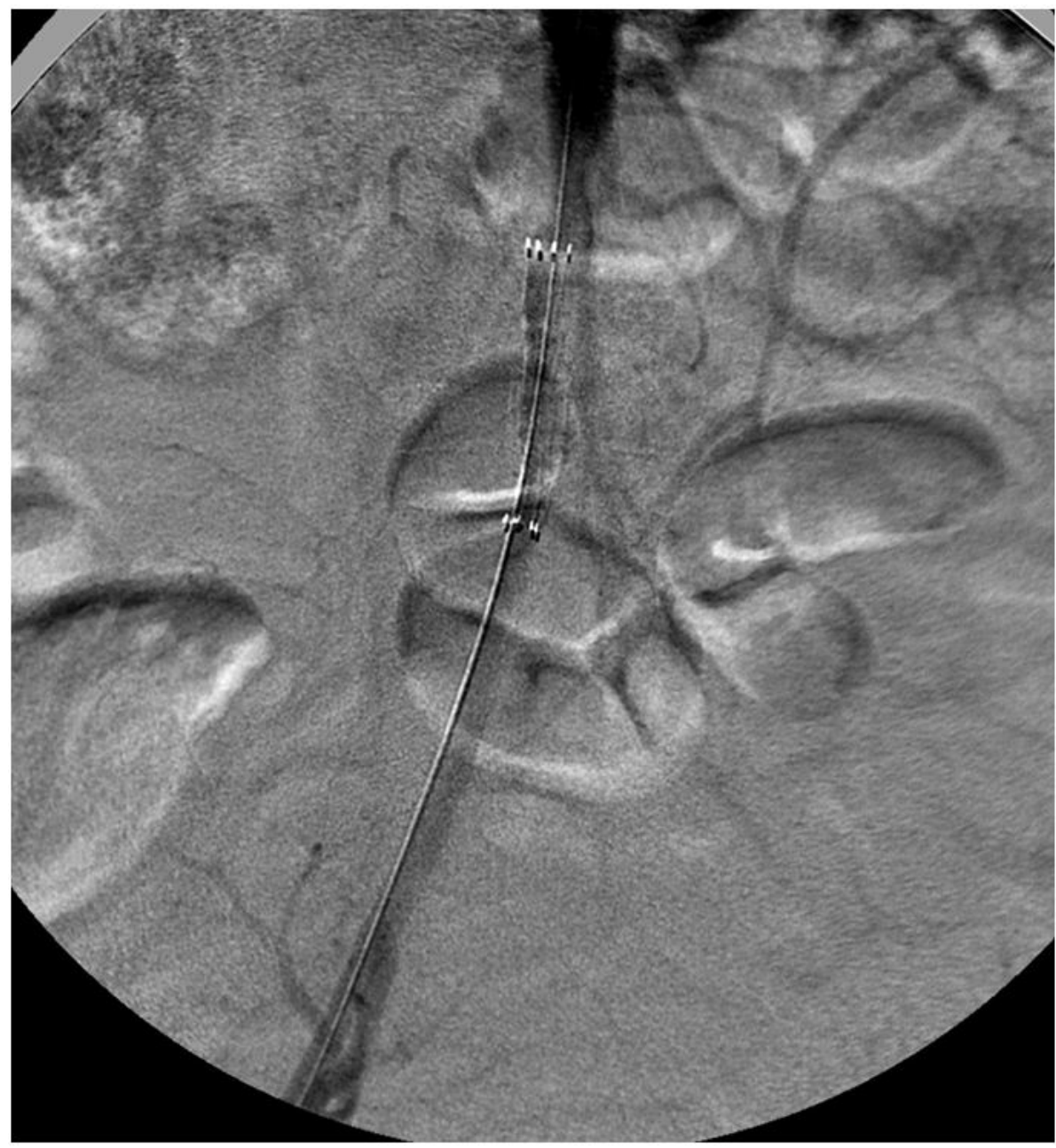

Figure 5: Nitinol stent positioning 


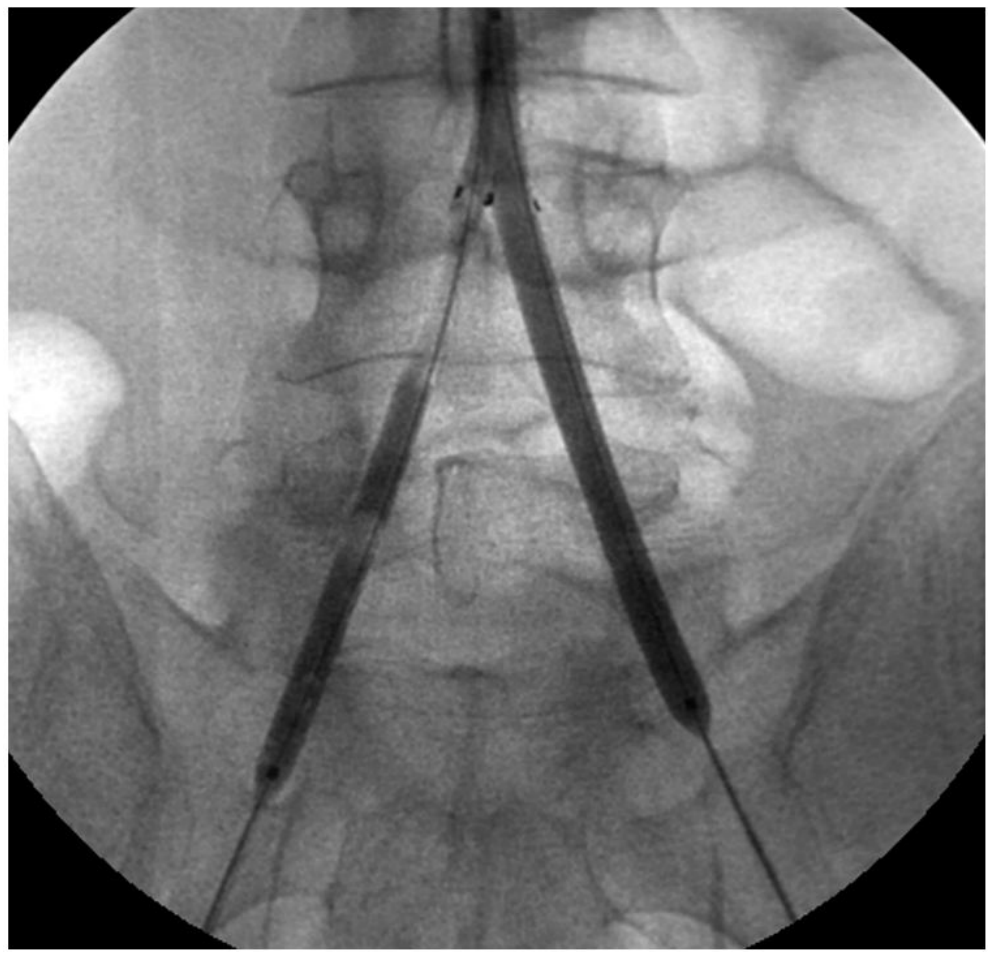

Figure 6: Kissing balloon technique

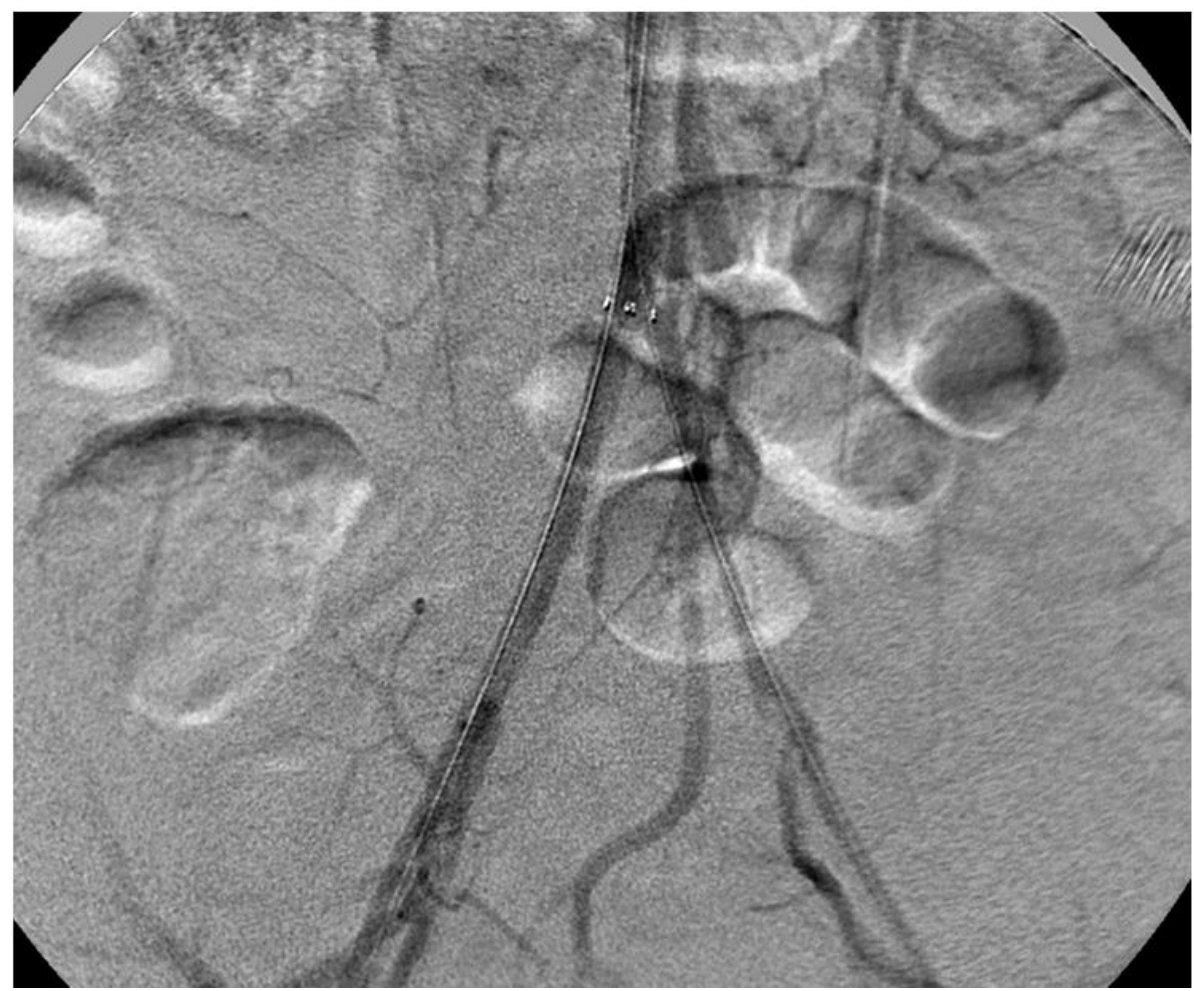

Figure 7: Regular and uniform opacity of infrarenal aorta and common iliac artery at control angiography

\section{Discussion}

According to Aorto-iliac Occlusive Disease (AIOD) classification by the Trans Atlantic Inter-Society Consensus (TASC II), Leriche Syndrome belongs to type D lesions, for which surgery is the recommended treatment of choice [4]. Surgical treatment consists in aorto-bifemoralbypass grafting $(\mathrm{ABF})$ from the infra-renal abdominal aorta to both femoral arteries, with transperitoneal or retroperitoneal approach. In some situations, due to anatomic considerations or clinical risks, an axillo-bifemoral or a unilateral axillo-femoral/aorto-femoralbypass with a femoro-femoral crossover may be used. Long-term primary patency rates for open bypass are undoubtedly superior to endovascular intervention [9]; however, secondary patency rates are comparable [5-7,10]. 
Considering that secondary endovascular interventions are often minor procedures, long-term outcomes are quite similar. Furthermore, open reconstructionsare related to higher operative morbidity, mortality [11,12], length of hospital stay [9,13] and short-term costs [14]. Evaluating percutaneous treatment, the risks of renal insufficiency, embolization and access complications are not insignificant; however, they can be prevented or managed without significant clinical consequence. Thus, the decision to choose open anatomic bypass is strongly challenged by percutaneous treatment, that should be considered a first-line treatment option for all patients with aortoiliac disease, especially for patients with an inoperable condition [15-17]. Quoting Clair DG and Beach JM, "the decision as to whether to choose anendovascular or open intervention requires a balance between the extent of thepatient's disease, the ability for thepatient to withstand a significant open operation without serious complication, and the surgeon's comfort and expertise in both open and endovascular aortoiliac procedures" [18].

A meta-analysis by Bosch and Hunink compared the results of aortoiliac PTA versus aortoiliac stenting: technical success and patency rates were higher for stenting, whereas complication rates and 30-day mortality rates did not differ significantly [8]. A multicenter study showed that PTA with provisional stenting had a similar outcome to primary stenting, in terms of 2-year reintervention rates [19] and thenumber of reinterventions at 5 years after treatment [20]. The stent length should cover the proximal end of the aortic lesion to within a centimeter of the aortic bifurcation. Regardless aortic stenting, the vessel disease of common iliac arteries is best treated with bilateral kissing balloons: they are advanced to approximately $5 \mathrm{~mm}$ above the aortic bifurcation, protected within their respective sheath. After the sheaths are retracted, the balloons are then synchronously deployed, evoking a kiss at angiography. Thrombolysis could be used as an adjunct to stenting in the treatment of aortoiliac occlusions, increasing the likelihood of crossing an aortoiliac occlusion [21] and anecdotally leading to decreased embolization to the visceral vessels and improved lysis. However, thrombolysis is associated with increased access site and other complications, as well as protracted treatment time and length of hospital stay due to infusion time.

\section{Conclusion}

Till now, percutaneous mechanical thrombectomy (PMT) has had a limited role in the treatment of aortoiliac occlusion due to the increased risk of embolization. Rotational thrombectomy with theRotarex ${ }^{\circledR}$ device (Straub Medical AG, Wangs, Switzerland) can minimize this risk, by achievingthe immediate aspiration of thrombotic debris simultaneously to mechanical thrombectomy. There is a lack of data in literature, regarding mechanical thrombectomy in percutaneous treatment of aortoiliac occlusion. Our experience sought to demonstrate that rotational mechanical thrombectomy, performed with Rotarex device, could be a feasible and safe solution as an adjunct to stenting. More data should be collected to assess if the adjunct of PMT really correlates with significant improvement in technical success, patency rates and complication rate compared to the only stenting in the percutaneous treatment of Leriche syndrome.

\section{References}

1. Leriche R, Morel A (1948) The syndrome of thrombotic obliteration of the aortic bifurcation. Ann Surg 127: $193-206$.

2. Diehm C, Diehm C, Schuster A, Allenberg JR, Darius H, et al. (2004) High prevalence of peripheral artery disease and co-morbidity in 6880 primary care patients: cross-sectional study. Atherosclerosis 172: 95-105.

3. Frederick M, Newman J, Kohlwes J (2010) Leriche Syndrome. J Gen Intern Med 25: 1102-4.

4. Norgren L, Hiatt WR, Dormandy JA, Nehler MR, Harris KA, et al. (2007) Inter-Society Consensus for the Management of Peripheral Arterial Disease (TASC II). J VascSurg 45: 10.1016/j.jvs.2006.12.037.

5. Jongkind V, Akkersdijk GJ, Yeung KK, Wisselink W (2010) A systematic review of endovascular treatment of extensive aortoiliac occlusive disease. J Vasc Surg 52: $1376-83$

6. Hans SS, DeSantis D, Siddiqui R, Khoury M (2008) Results of endovascular therapyand aorto-bifemoral grafting for Transatlantic Inter-Society type C and Daortoiliac occlusive disease. Surgery 144: 583-9.

7. Kashyap VS, Pavkov ML, Bena JF, Sarac TP, O'Hara PJ, et al. (2008) The management of severe aortoiliac occlusive disease:endovascular therapy rivals open reconstruction. J Vasc Surg 48: 1451-7.

8. Bosch JL, Hunink MG (1997) Meta-analysis of the result of percutaneous transluminal angioplasty and stent placement for aortoiliac occlusive disease. Radiology 205: 87-96.

9. Psacharopulo D, Ferrero E, Ferri M, Viazzo A, Singh Bahia S, et al. (2015) Increasing efficacy of endovascular recanalization with covered stent graft for TransAtlantic Inter-Society Consensus II D aortoiliac complex occlusion. J Vasc Surg 62: 1219-26.

10. Kim T-H, Ko Y-G, Kim U, Kim JS, Choi D, et al. (2011) Outcomes of endovascular treatment of chronic total occlusion of the infrarenal aorta. J Vasc Surg 53: 1542-9.

11. Ligush J, Criado E, Burnham SJ, Johnson G Jr, Keagy BA (1996) Management and outcome of chronic atherosclerotic infrarenal aortic occlusion. J Vasc Surg 24: $394-404$

12. García-Fernández F, Marchena Gómez J, Cabrera Morán V, Hermida M, Sotgiu E, et al. (2011) Chronicinfrarenal aortic occlusion: predictors of surgical outcome in patients undergoing aortobifemoral bypass reconstruction. J Cardiovasc Surg 52: 371-80.

13. West CA, Johnson LW, Doucet L, Caldito G, Heldman M, et al. (2010) A contemporary experience of open aortic reconstruction in patients with chronic atherosclerotic occlusion of the abdominal aorta. J Vasc Surg 52: 1164-72.

14. Indes JE, Mandawat A, Tuggle CT, Muhs B, Sosa JA (2010) Endovascular procedures for aorto-iliac occlusive disease are associated with superior short-term clinical and economic outcomes compared with open surgery in the inpatient population. J Vasc Surg 52:1173-9.

15. Nomura A, Nagashima M, Tomoi Y, Tosaka A, Soga Y (2015) Successful endovascular treatment for high take off aorto-iliac occlusive disease. Intern Med 54: 921-4. 
16. Mangialardi N, Ronchey S, Serrao E, Fazzini S, Alberti V, et al. (2017) Endovascular management of total juxtarenal aortic occlusive disease in high-risk patients: technical considerations and clinical outcome. J Cardiovasc Surg 58: 422-30.

17. Van Haren RM, Goldstein LJ, Velazquez OC, Karmacharya J, Bornak A (2017) Endovascular treatment of TransAtlantic Inter-Society Consensus D aortoiliac occlusive disease using unibody bifurcated endografts. J Vasc Surg 65: 398-405.

18. Clair DG ,Beach JM (2015) Strategies for managing aortoiliac occlusions: access, treatment and outcomes. Expert Rev Cardiovasc Ther 13: $551-63$.

19. Tetteroo E, van der Graaf Y, Bosch JL, van Engelen AD, Hunink MG, et al. (1998) Randomised comparison of primary stent placement versus primary angioplasty followed by selective stent placement in patients with iliac-artery occlusive disease. Lancet 351: 1153-9.

20. Klein WM, van der Graaf Y, Seegers J, Moll FL, Mali WP (2004) Long-term cardiovascular morbidity, mortality, and reintervention after endovascular treatment in patients with iliac artery disease. Radiology 232: 491-8.

21. Motarjeme A, Gordon GI, BodenhagenK (1995) Thrombolysis and angioplasty of chronic iliac artery occlusions. J Vasc Interv Radiol 6: 66S-72S

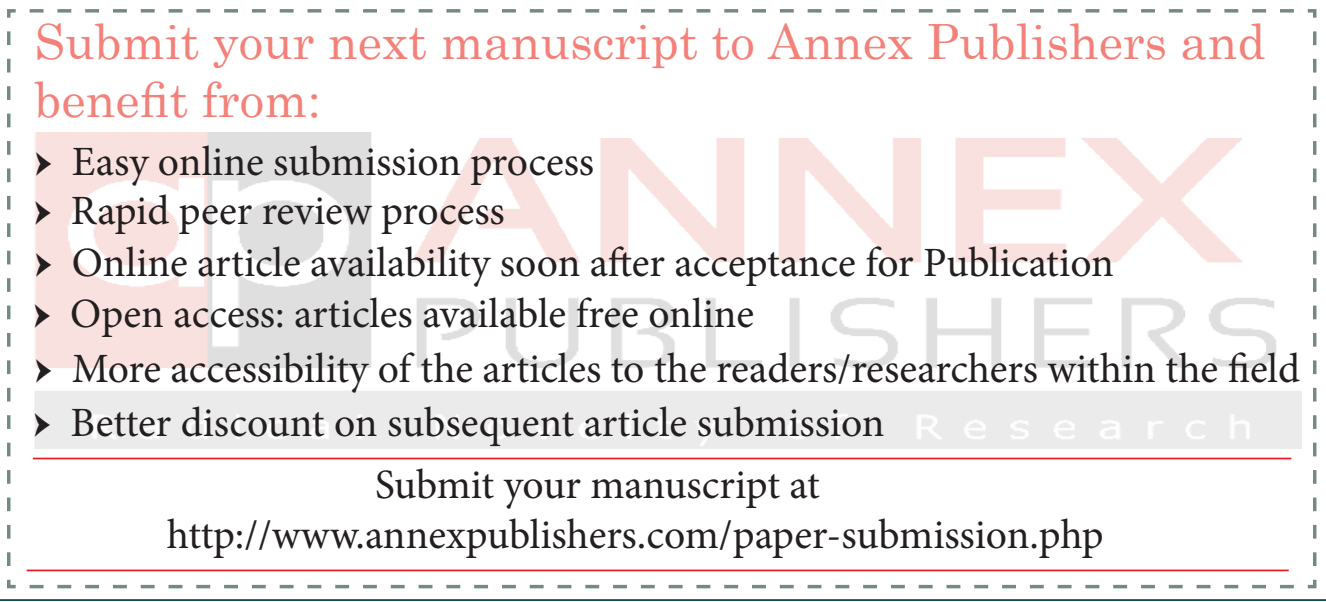

